\title{
Comment on the Annual Lecture of Professor Walter A. Weisskopf "Reflections on Uncertainty"
}

\author{
by Fabio Padoa*
}

We shall never see the end of uncertainty and risk.

I. Prigogine

1. The increasing tendency to draw a parallel between the development of one scientific field and another is a sound reaction to the subdivision of sciences which we inherited from 19th century positivism, with its simple trust in specialized knowledge. The modern scientist is no longer satisfied with his knowing more and more about less and less: he needs a general framework for his specific knowledge. We have not yet re-discovered the classical unity of truth and beauty Goethe had derived from the Renaissance, and the latter from Ancient Times, but already physics combines with philosophy, sociology resorts to biology, ethnology adopts the instruments of linguistics. So that, when Professor Weisskopf draws a parallel between the evolution of a science which is still as young as economics and the shining milestones of physics, he opens up a stimulating path.

At first sight, the physicist's approach may be taken for granted, when he reaches some of the truths that the theoretical thought of philosophers has already disclosed. A critical reading of Spinoza already denounced strict determinism as fundamentally sterile, before Newton's and Laplace's predictable world deprived man from his original freedom. Similarly, Kant stated it was impossible to know the thing in itself, before Broglie and Heisenberg recognized that the observer's presence modifies the object observed. Furthermore, long before Niels Bohr's theories, Hegel and Croce had acknowledged the indissoluble bond between freedom and necessity : according to them, freedom exists only in a given situation, so that it is always subject to certain conditions.

If the scientist, exploring nature now, either finds the same obstacles in his way, or the same solutions to the problems on which for centuries philosophers have concentrated their abstract thought, this implies a significant confirmation of the unity of the human spirit. Let us, therefore, welcome without surprise the troublesome coincidences between the progress of research in the natural sciences and the study of economics.

* Honorary President of the Geneva Association. 
2. But to come to the very subject of my remarks as an insurer, let me, first of all, tell Professor Weisskopf, how much I did appreciate his remark concerning the limited place insurance would necessarily take in the deterministic Spinozian or Newtonian world, where the future might be predicted with certainty, provided all causes were perfectly known. It is an important remark indeed : insurance has been rather neglected by economists up to the recent past ; as a mean to reduce uncertainty and gauge its impact, it was not felt to be a necessary component of one's satisfactory interpretation of reality. Such an approach obviously changes, if the future can no longer be safely predicted, according to Heisenberg's indeterminateness. If uncertainty becomes part of any conception of the future, we shall feel naturally inclined to restrain its scope and to define its range. Therefore, any technique suitable to bring back into the field of the known or that of the knowledgeable an even limited part of the unpredictable future, is worth taking into consideration ; it might even be used as a model in other fields. This is precisely the type of technique adopted by insurance which, within the economic sphere, replaces with certainties the hazards of the individual destiny. It is not surprising then, that a few economists, more alert than others to contemporary reality, recognize uncertainty as the variable their predecessors had not taken into proper consideration, bound as they were to an exactly determinable world. As a result of the failure of traditional doctrines, which prove more and more unable to provide remedies for many ills of our age - from unemployment to monetary inflation - these economists feel that risk and uncertainty have been neglected. Progressive minds like Arrow, Borch, Drèze, Giarini agree on this point, thus opening the path to the economists of the Geneva group.

3. When attention is drawn to insurance, with regard to the parallel development of physics and economics, as Professor Weisskopf suggests, several contact points appear. I would detect at least three of them. I am not sure whether they are merely fortuitious, and as such just curious, or whether they confirm a deep resemblance between the two fields and deserve closer attention.

To begin with, for insurance truth is always and only a statistical truth. Just as in the Brownian movements, where the course of a single molecule cannot be foreseen but the average of the course of a universe of molecules and their effect can be exactly forecasted, an insurer can calculate, and therefore foresee, the sum of events of the same nature which are going to take place within a given population, even though he cannot say beforehand which of its members will be involved. So, he bases his calculations on a statistical truth which appears to be absolutely reliable. Thus, his activity provides the economist with ground for observation and, maybe, for actual experiment. From the point of view of insurance, the individual uncertainty becomes a collective certainty. If we transpose the terms of the conflict occurring in the study of nature, into the economic field, we might consider the patterm of insurance as a sort of link between these two positions: Newton stressing the predictable aspects of reality, Heisenberg giving prominence rather to the notion of probability instead of that of certainty. Insurance, by building a bridge between the collective statistical certainty and the individual uncertainty, makes it possible to limit the impact of a future event, since this can be calculated in advance. From this viewpoint, insurance deserves a place of its own in the economic theory, progressing from an outlook of static certainty to a concept of dynamic uncertainty of the future. 
Secondly, Heisenberg and Broglie do not show the physical world as a mechanism, but rather as a system, the properties of which cannot be reproduced into smaller units : the sum of the parts differs from the whole. The same applies to the world of insurance, where any change of the components is reflected by all the others, and an isolated part does not reproduce the characteristics of the whole. One might even say that the behaviour of each component is modified by its belonging to the group. Here, in a merely economic field, there is a striking analogy with the description the physicist gives us as regards matter, seen in the infinitesimal scale. One cannot help recognizing that, from this point of view, insurance gives the observer of economic facts interesting ground for analysis. In truth, if the economist finds it interesting to consider his activity from the angle of modern theories of knowledge, the theorist may find it useful to direct his mind to the analogies of a field in which some scientific principles are put into practice, so that one is in a position to measure and verify them.

Lastly, Heisenberg's findings, while depriving man of his power of knowledge and, therefore, of forecast, endows him with freedom of action ; man becomes an actor, I would say even a main character of the creative evolution, using Teilhard de Chardin's concept. In the economic field, the hero of this re-discovered freedom is Schumpeter's adventurous entrepreneur, whose creative dynamism moves progress. An entrepreneur is, basically, a man who takes risks. He does not, of course, take any kind of risk, on the contrary, success will reward the wise entrepreneur who, after an accurate analysis of the risks involved and not only the enterprise risk, in the strictest sense of the word - will keep on the safe side. Now, do not risk analysis and risk management cover exactly the role of the insurer? It has always been so, and even more today, when the increasingly complex industrial world and, paradoxically, the progress of technology make any enterprise more vulnerable than in the past. We see it in the success of risk management which in its widest meaning is nothing else than management itself. Here is another aspect of the insurance technique which deserves attention, since it gives the entrepreneur unexpected prospects to play his role to the best of his power.

4. Let us now enlarge upon our considerations. Professor Weisskopf tells us that it is not by accident that we live in this era of anxiety. Beliefs, myths, superstitions, ideologies have lost little by little part of their reassuring power. Even science, far from stressing, as it used to, the trust in its almighty power, emphasizes the uncertainty of modern man as an ontological condition. Modern man, although better-off than his ancestors and relying on social structures likely to guarantee his welfare, is still at the mercy of uncertainty and fear.

Might it not be that this freedom of action, that contemporary science restores, is denied to man by the very social structures meant to protect him ? If the so-called social security disappoints him, might it not be because it does not give him a chance to make his own choice and accomplish an effort for himself? Might it not be that because, in this context, he has no chance to assume his own responsibilities? Now, on the contrary, private insurance provides each individual with an opportunity to calculate his chances and keep off some future risks by his own voluntary effort. Thus, within the comprehensive context of insurance, a striking gap appears between two different ways of meeting the search for security : one asking only for passive acceptance and conformity, the other based on personal decisions and direct efforts. While the first one fails to reach its main aim of 
granting collective security, the second one rewards the efforts of volunteers who prove to be prepared to share the burden of a mutual aid.

Here as well, economists and sociologues might be interested in directing their attention to insurance and to the role played by freedom of action in reaching a successful system of meeting the need of security, by giving anybody an opportunity to measure his own chances and restricting the range of the invevitable.

5. Let us now come to the conclusion of Professor Weisskopf's paper.

If, in harmony with the new tendencies in the science of nature, economic theory, abandoning its contemplative attitude, turns to action, the moral problem does necessarily arise. What kind of action are we talking about? Undoubtedly, in economics, action is governed by a utilitarian criterium of interest, while, in the moral sphere, it aims at universal targets. But these two aspects of the practical mind - id est economics and moral science - are not necessarily opposed to each other. Our action, as Benedetto Croce says, will produce no lasting satisfaction, unless it is moved by a sense of duty, unless it pursues universal significance, beyond individual targets. Such an ideal stays alive in every man. It only has to be given opportunities to show up. It will undoubtedly materialize, as Professor Weisskopf recalls, when a man gives his contribution to the achievement of a public scheme, regardless of the political ideology inspiring it. But it will be more definitely configured in free associations of people: for instance, in a mutual venture, where individual advantage and common protection are tied together. Now, private insurance is nothing but organized mutuality in the shape of an enterprise. In both cases the inner attitude and the motivating will of participants - in other words, the level of their conscience - will determine the quality of their actions.

Not long ago, economics used to be regarded as part of moral philosophy. Nobody wishes to take its scientific autonomy away. But in showing the underlying unity in the progress of spirit, Professor Weisskopf makes us feel that moral science cannot be disregarded, when taking advantage of the freedom of action the new discoveries of natural sciences provide us with. 